\title{
SYNTHESIS, CHARACTERIZATION AND APPLICATION OF A DIATOMITE-BASED COMPOSITE FOR THE ADSORPTION OF ANIONIC DYES IN AQUEOUS SOLUTIONS
}

\author{
Sadek Chentouf ${ }^{1}$, Smail Kacha ${ }^{2}$, Réda Marouf ${ }^{1,}{ }^{凶}$, Fouad Mekhalef Benhafsa ${ }^{2,3}$, \\ Abdelkader Leboukh ${ }^{2}$, Ahmed Yahiaoui ${ }^{4}$
}

https://doi.org/10.23939/chcht15.03.377

\begin{abstract}
Synthesis, characterization and application of the polyaniline-diatomite (PAD) composite in the adsorption of Reactive Red 120 (RR 120) and Acid Blue (AB) dyes were carried out. The composite was prepared by the in situ polymerization of aniline. Mass of purified diatomite was mixed with a solution containing aniline dissolved in $2 \mathrm{M}$ hydrochloric acid at room temperature. The solid obtained was characterized using the SEM, XRD and FTIR analyses. The kinetic adsorption of dyes was described using the pseudo-second order kinetic model. The adsorption isotherm of the RR 120 dye can be fitted by the Freundlich adsorption isotherm model. However, the adsorption isotherm of the $\mathrm{AB}$ dye can be better fitted by the BET model.
\end{abstract}

Keywords: adsorption, anionic dyes, characterization, diatomite, polyaniline, synthesis.

\section{Introduction}

Synthetic dyes are widely used by some industries, such as textile industry, tanneries, pulp and paper industry or plastics and paints industry. Discharges from these industrial plants are generally heavily loaded with dyes and auxiliaries, most of which are toxic, poorly biodegradable and often resistant to biological treatments $[1,2]$. Among the techniques used for the purification of wastewaters, adsorption is that which has been widely

\footnotetext{
${ }^{1}$ Laboratory of Materials, Applications and Environment, Mustapha Stambouli University, P.B. 305 Mamounia road, Mascara 29000, Algeria

${ }^{2}$ Laboratory of Advanced Materials and Physicochemistry for the Environment and Health (MAPES),

Djillali Liabes University, P.B. 89 Sidi Bel Abbes 22000, Algeria

${ }_{3}^{3}$ Scientific and Technical Research Center on Physical and Chemical

Analyses (CRAPC), Industrial Zone Bou-Ismail, Tipaza, Algeria

${ }^{4}$ Laboratory of Organic Chemistry, Macromolecular and Materials,

Mustapha Stambouli University, P.B. 305 Mamounia road, Mascara 29000, Algeria

r.marouf@univ-mascara.dz

(c) Chentouf S., Kacha S., Marouf R., Benhafsa F., Leboukh A., Yahiaoui A., 2021
}

studied $[3,4]$. This technique consists of fixing polluting molecules or ions, called adsorbates, on solid materials dispersed in water, called adsorbents. Adsorption is one of the processes that are actually widely used for dye removal; it also has wide applicability in wastewater treatment [5]. Adsorption is a method that has always been considered superior to other techniques for optimizing the reuse of treated water in terms of initial cost, flexibility and simplicity of design, ease of use and insensitivity to toxic pollutants. Also, adsorption does not result in the formation of harmful substances either [6].

Some adsorbent materials have been used in their natural state, but sometimes they need to undergo some modifications to improve their adsorbent capacities [7]. Diatomite, which is among the materials tested at the laboratory scale, has been the subject of several studies as an adsorbent to remove dyes from water. The diatomite is a nearly pure sedimentary deposit consisting almost entirely of silica. It derives from a siliceous sedimentary rock consisting mainly of fossil skeletal remains of diatoms. The diatom is a seaweed-related unicellular aquatic plant formed during the tertiary and quaternary periods $[8,9]$. The highly porous structure, low density and high surface area have given rise to many industrial applications of diatomite as adsorbent for many organic contaminants [10].

Acid and reactive dyes, generally used on cotton and other synthetic fibers, are also used, to a lesser extent, on wool and nylon. These dyes form a covalent bond with the fiber and contain chromophore groups such as azobased compounds, anthraquinone, triarylmethane, phthalocyanine, formazan, oxazine, etc. [11, 12]. As these dyes are highly soluble in water and they pose serious problems regarding their removal from water [13, 14]. Various modifications have been proposed and tested to make diatomite more efficacious and cost-effective in dye fixation. Elden et al. [10] and Khreisheh et al. [15] modified the diatomite by calcination at the temperature of $1253 \mathrm{~K}$ and used it to remove methylene blue, reactive yellow and reactive black. They found out that the diatomite thus modified loses its hydroxyl groups. The 
adsorption capacities obtained were moderate (between 16.99 and $28.35 \mathrm{mg} / \mathrm{g}$ ). Jian et al. [16] modified diatomite by sodium hydroxide treatment to apply it in the elimination of methylene blue; the adsorption capacity obtained in this case was also moderate $(18.15 \mathrm{mg} / \mathrm{g})$.

Recently, an interesting transformation of the surface of diatomite by polyaniline gave rise to $92 \%$ diatomite composite $[17,18]$. This composite, initially synthesized for the purpose of having a conductive material, has attracted our attention in order to test its adsorbent capacities with respect to the adsorption of water-soluble anionic dyes.

The present work aims to study the kinetics and adsorption isotherms of Reactive Red 120 (RR 120) and Acid Blue 113 (AB 113) on the polyaniline-diatomite (PAD) composite. These dyes are azo compounds and anionic in solution and these types of dyes are very harmful to human health. They are also highly soluble in water, which makes them very difficult to eliminate. The kinetics and isotherms were modeled to elucidate the mechanisms governing the adsorption of $\mathrm{RR}$ and $\mathrm{AB}$ onto $\mathrm{PAD}$ composite.

\section{Experimental}

\subsection{Diatomite}

The diatomite used in this study comes from the town of Sig, in the region of Mascara (northwestern Algeria). Diatomite is a very light siliceous rock, pure, powdery, and very porous, finely laminated brilliantly white and has high silica content (Table 1). To remove calcite, the diatomite suspension was brought into contact with a solution of hydrochloric acid $(\mathrm{pH}=4)$ under continuous stirring, for $2 \mathrm{~h}$. The suspension was then allowed to settle overnight, before separating the insoluble solids from liquid and washing several times with distilled water to remove excess $\mathrm{CaCl}_{2}$ and $\mathrm{HCl}$. Finally, the paste obtained was baked at $383 \mathrm{~K}$ for $24 \mathrm{~h}$ and then ground until a fine powder of purified diatomite was obtained.

\subsection{Preparation of the PAD Composite}

The polyaniline/diatomite composite was prepared using the so-called "one-step" method, i.e. by the in situ polymerization of aniline. The method was described by Li et al. [18]. $1 \mathrm{~g}$ of purified diatomite was brought into contact with a solution containing $1 \mathrm{ml}$ of aniline dissolved in $80 \mathrm{ml}$ of $2 \mathrm{M}$ hydrochloric acid $(\mathrm{HCl})$. The reaction mixture was stirred magnetically for $10 \mathrm{~h}$ at room temperature. The admixture thus obtained was mingled with $1 \mathrm{~g}$ of ammonium persulfate $\left(\mathrm{NH}_{4}\right)_{2} \mathrm{~S}_{2} \mathrm{O}_{8}$ previously dissolved in $20 \mathrm{ml}$ of distilled water and kept under magnetic stirring for $5 \mathrm{~h}$. The product obtained was the PAD composite which was first filtered and then washed three times with distilled water to remove traces of the monomer and oxidant. It was finally dried at $333 \mathrm{~K}$ for $24 \mathrm{~h}$ and stored in glass vials.

\subsection{Dyes}

The dyes used in this study are industrial dyes belonging to the family of azo dyes; they are anionic in aqueous solution. The Reactive Red 120 (Sigma) with 50 $70 \%$ purity was used after hydrolysis, according to the method described by Bouyakoub et al. [19]. This method consisted of dissolving $0.1 \mathrm{~g}$ of RR dye in one liter of distilled water in the presence of $1 \mathrm{~g}$ of $\mathrm{NaHCO}_{3}$. The solution thus prepared was then heated at the temperature between 323 and $343 \mathrm{~K}$ for $15 \mathrm{~min}$ in order to simulate the conditions applied in the dye baths. The freshly prepared solution was used as a stock solution. The Acid Blue (Aldrich) with $50 \%$ purity was used without any prior treatment, and $0.1 \mathrm{~g}$ of $\mathrm{AB}$ dye was dissolved in 11 of distilled water at room temperature and used as a stock solution. Fig. 1 illustrates the molecular structures of both dyes and their main characteristics are given in Table 2.

Table 1

Chemical composition of diatomite

\begin{tabular}{|c|c|c|c|c|c|c|c|c|c|}
\hline Oxide & $\mathrm{SiO}_{2}$ & $\mathrm{CaO}$ & $\mathrm{Al}_{2} \mathrm{O}_{3}$ & $\mathrm{Fe}_{2} \mathrm{O}_{3}$ & $\mathrm{~K}_{2} \mathrm{O}$ & $\mathrm{MgO}$ & $\mathrm{Na}_{2} \mathrm{O}$ & $\mathrm{TiO}_{2}$ & $\mathrm{MnO}$ \\
\hline$\%$ & 68.017 & 19.252 & 7.575 & 2.022 & 1.491 & 1.241 & 0.200 & 0.144 & 0.038 \\
\hline
\end{tabular}

Table 2

Main characteristics of dyes

\begin{tabular}{|c|c|c|}
\hline Generic name & Reactive Red 120 & Acid Blue 113 \\
\hline Symbol & RR & BA \\
\hline Classification & Reactive dye & $3351-05-1$ \\
\hline CAS Number & $61951-82-4$ & 681.65 \\
\hline Molecular Weight, g.mol ${ }^{-1}$ & 1469.98 & $\mathrm{C}_{32} \mathrm{H}_{21} \mathrm{~N}_{5} \mathrm{O}_{6} \mathrm{~S}_{2} \mathrm{Na}_{2}$ \\
\hline Linear Formula & $\mathrm{C}_{44} \mathrm{H}_{24} \mathrm{CI}_{2} \mathrm{~N}_{14} \mathrm{O}_{20} \mathrm{~S}_{6} \mathrm{Na}_{6}$ & 50 \\
\hline Composition dye content, $\%$ & $50-70$ & 566 \\
\hline$\lambda_{\max }, \mathrm{nm}$ & $530 *$ & 56 \\
\hline
\end{tabular}

Note: * after hydrolysis 


\subsection{Adsorption Experiment}

All the adsorption tests were carried out in $100 \mathrm{ml}$ beakers, containing $50 \mathrm{ml}$ of aqueous solutions each having a desired initial dye concentration $(\mathrm{mg} / \mathrm{l})$, kept under magnetic stirring at $400 \mathrm{rpm}$, at the temperature of $293 \mathrm{~K}$ during a definite contact time. To determine the influence of the adsorbent dosage on the adsorption efficiency, increasing PAD doses were added separately. The influence of the initial $\mathrm{pH}$ of colored solutions on the adsorption efficiency was studied using aqueous solutions of $\mathrm{HCl}$ and $\mathrm{NaOH}$ at concentration $0.1 \mathrm{M}$. The maximum wavelength $\lambda_{\max }$ of the dyes was determined and the absorbance measurement of dye solutions was performed using a VIS7220 G spectrophotometer (Biotech Engineering Management). The $\mathrm{pH}$ of the solutions was measured using a $\mathrm{pH}$ meter (AD8000, ADWA, Romania). The percentage removal of the dye was obtained using Eq. (1):

$$
\text { Percentage removal dye }=\frac{C_{0}-C_{e}}{C_{0}} \cdot 100
$$

where $C_{0}$ and $C_{e}$ are the initial and equilibrium concentrations of the dye in solution, $\mathrm{mg} / \mathrm{l}$.

The amount of dye adsorbed per unit mass of adsorbent, at any time or at equilibrium, was calculated by means of the following formula:

$$
\text { Adsorption capacity }=\frac{\left(C_{0}-C_{f}\right) \cdot V}{m}
$$

where $C_{f}$ is the final concentration of dye solution, $\mathrm{mg} / \mathrm{l}$; $V$ is the volume of colored solution, 1 ; and $m$ is the adsorbent mass, $g$.

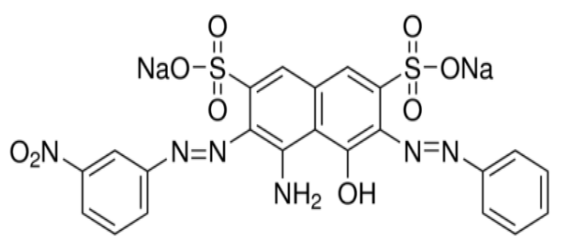

b)

Fig. 1. Chemical structure of Reactive Red 120 (a) and Acid Blue 113 (b)

\section{Results and Discussion}

\subsection{Characterization of the PAD Composite}

\subsubsection{Scanning electron microscope images}

Scanning electron microscopy (SEM) has been used as an effective tool for the characterization of physical properties of the adsorbent surface. Fig. 2 depicts SEM images of the diatomite and PAD composite. Comparison of two images indicates that certain parts of the surface of the diatomite are occupied by the polyaniline particles. The composite thus formed shows a heterogeneous surface. Indeed, the specific surface of diatomite is the seat of polyaniline molecules. Li et al. [17] indicated that a composite with $92 \%$ diatomite could be obtained from this preparation. Moreover, Li et al. [18] noted that the PAD specific surface area is lower than that of crude diatomite, while the total pore volume was higher. This new feature acquired by the modified diatomite allows this composite to offer channels that can accommodate multiple layers of dyes. These findings enhance the deposition of polyaniline particles on the diatomite surface.

\subsubsection{X-ray diffraction (XRD)}

The X-ray diffractograms of diatomite and PAD are illustrated in Fig. 3. This figure shows that the main peaks related to the diatomite sample correspond to quartz, cristobalite, and a mixture of smectite and kaolinite with smaller amounts of hematite. The X-ray diffractogram of crude diatomite is different from that of polyaniline-modified diatomite. In addition, it can be noted that the quartz peaks decreased remarkably, while those related to smectite-kaolinite mixture and hematite completely disappeared after the modification of diatomite by the PAD. Moreover, the X-ray diffractograms show that the diatomite structure has been drastically altered, with a loss of crystallinity in favor of a more amorphous structure. Indeed, some peaks of the diatomite disappeared while some others with lower intensity appeared during the transformation. Similar behavior was reported by Gao et al. [20].

\subsubsection{Fourier-transform infrared spectroscopy (FTIR)}

Fig. 4a illustrates the main absorption bands of the diatomite used. The bands at 1054, 874, 798, 711, 518, and $460 \mathrm{~cm}^{-1}$ were particularly remarked. The $1054 \mathrm{~cm}^{-1}$ 
band represents the (-Si-O- $\mathrm{Si}-)$ elongation of the siloxane group and the band at $874 \mathrm{~cm}^{-1}$ corresponds to the $\mathrm{Si}-\mathrm{O}$ elongation of the silanol group. The bands at 798 and $711 \mathrm{~cm}^{-1}$ are attributed to the vibrations of the $\mathrm{SiO}-\mathrm{H}$ bonding. Absorption peaks around 518 and $460 \mathrm{~cm}^{-1}$ are attributed to $\mathrm{Si}-\mathrm{O}-\mathrm{Si}$ bending vibrations. The diatomite absorption bands that usually appear near 3690 and $3614 \mathrm{~cm}^{-1}$ due to the free silanol group ( $\left.\mathrm{SiO}-\mathrm{H}\right)$ and were reported by some authors such as Khraisheh et al. [15], were not very visible on the spectrum probably because of the acid treatment of diatomite. Fig. $4 \mathrm{~b}$ shows the absorption bands of PAD composite. In this figure, one can clearly see that in addition to the characteristic peaks of diatomite, there are also peaks corresponding to polyaniline.

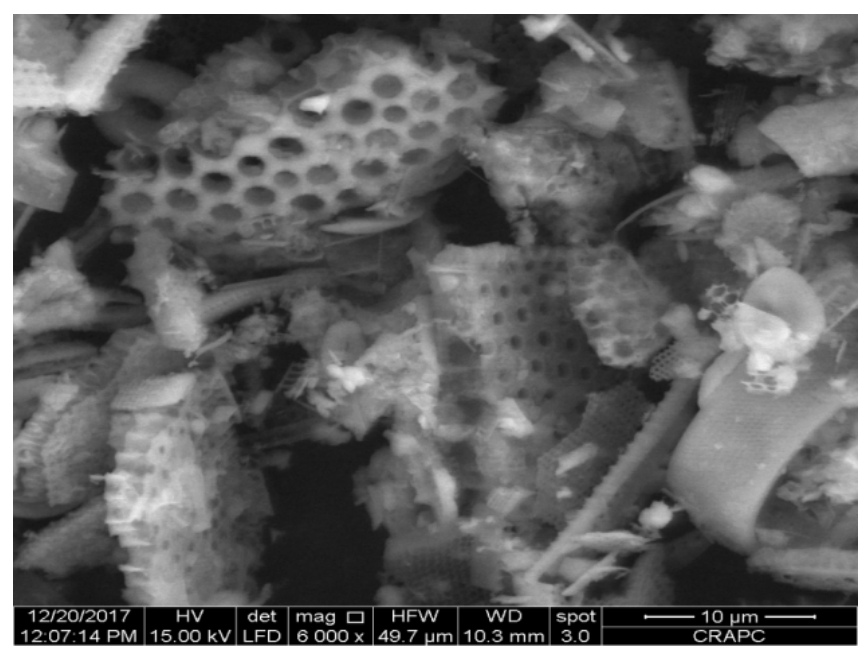

a)
In Fig. 4b, the FTIR spectrum of the PAD composite clearly shows the contributions of both polyaniline and diatomite. The characteristic peaks of polyaniline are those which appeared at 1558 and $1475 \mathrm{~cm}^{-1}$, and which are attributable to the $\mathrm{C}=\mathrm{N}$ and $\mathrm{C}=\mathrm{C}$ elongations of the quinoid and benzenoid rings, respectively. Peaks at 1304 and $1235 \mathrm{~cm}^{-1}$ are attributed to the $\mathrm{C}-\mathrm{N}$ stretching of the benzenoid ring. However, it is difficult to determine the origin of the other absorption peaks of this composite because diatomite and polyaniline can absorb at similar wave numbers. It is also noted, comparing Figs. $4 \mathrm{a}$ and $4 \mathrm{~b}$, that some peaks of diatomite were displaced due to its interaction with polyaniline. For example, the peak at $798 \mathrm{~cm}^{-1}$, which formed during modification, changed to a lower wave number (from 798 to $793 \mathrm{~cm}^{-1}$ ).

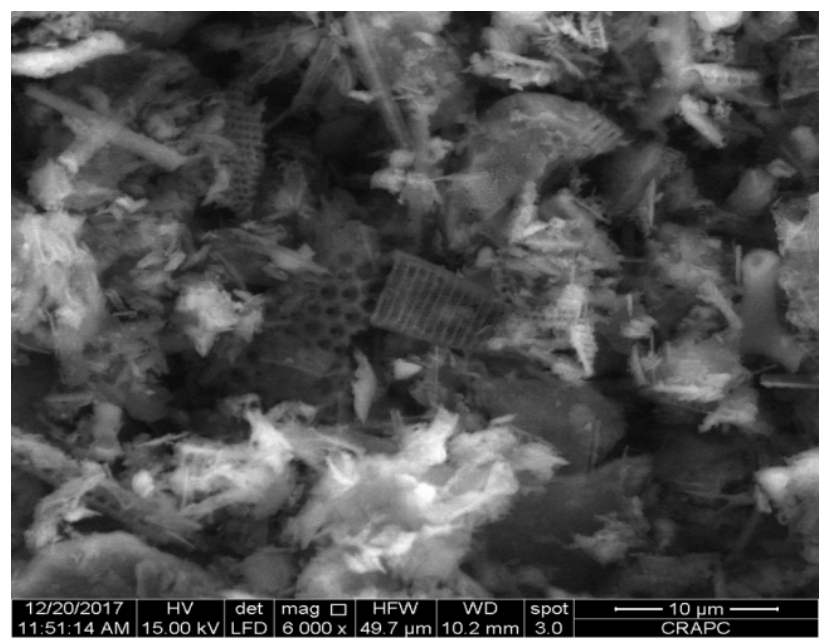

b)

Fig. 2. SEM images of diatomite (a) and PAD composite (b)

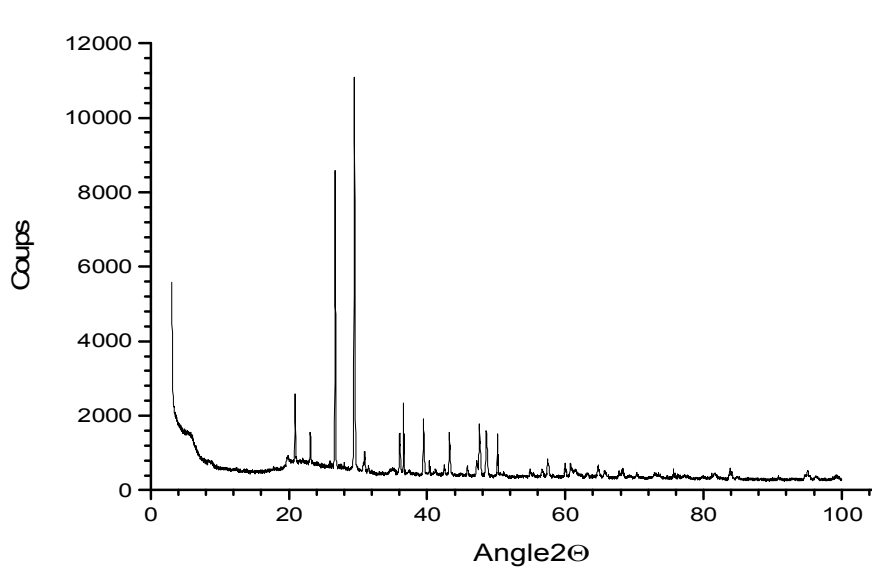

a)

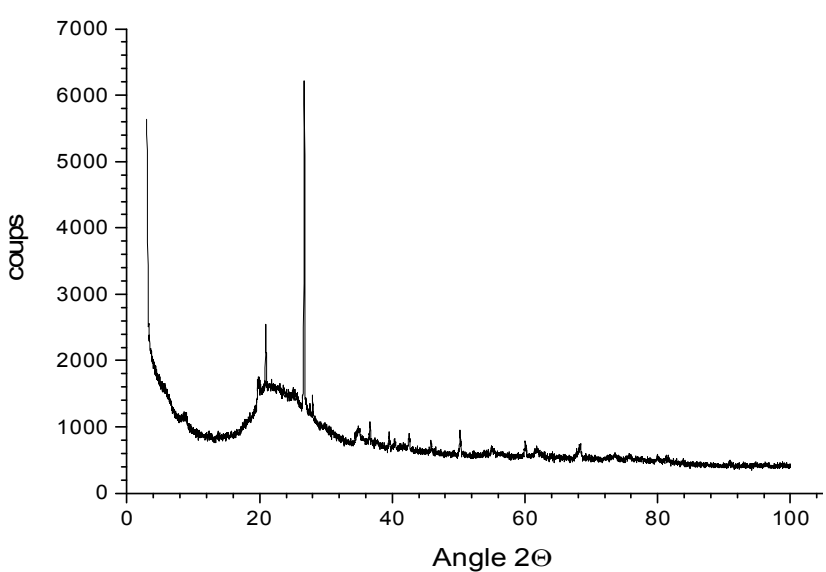

b)

Fig. 3. X-ray diffractograms of diatomite (a), and PAD composite (b) 

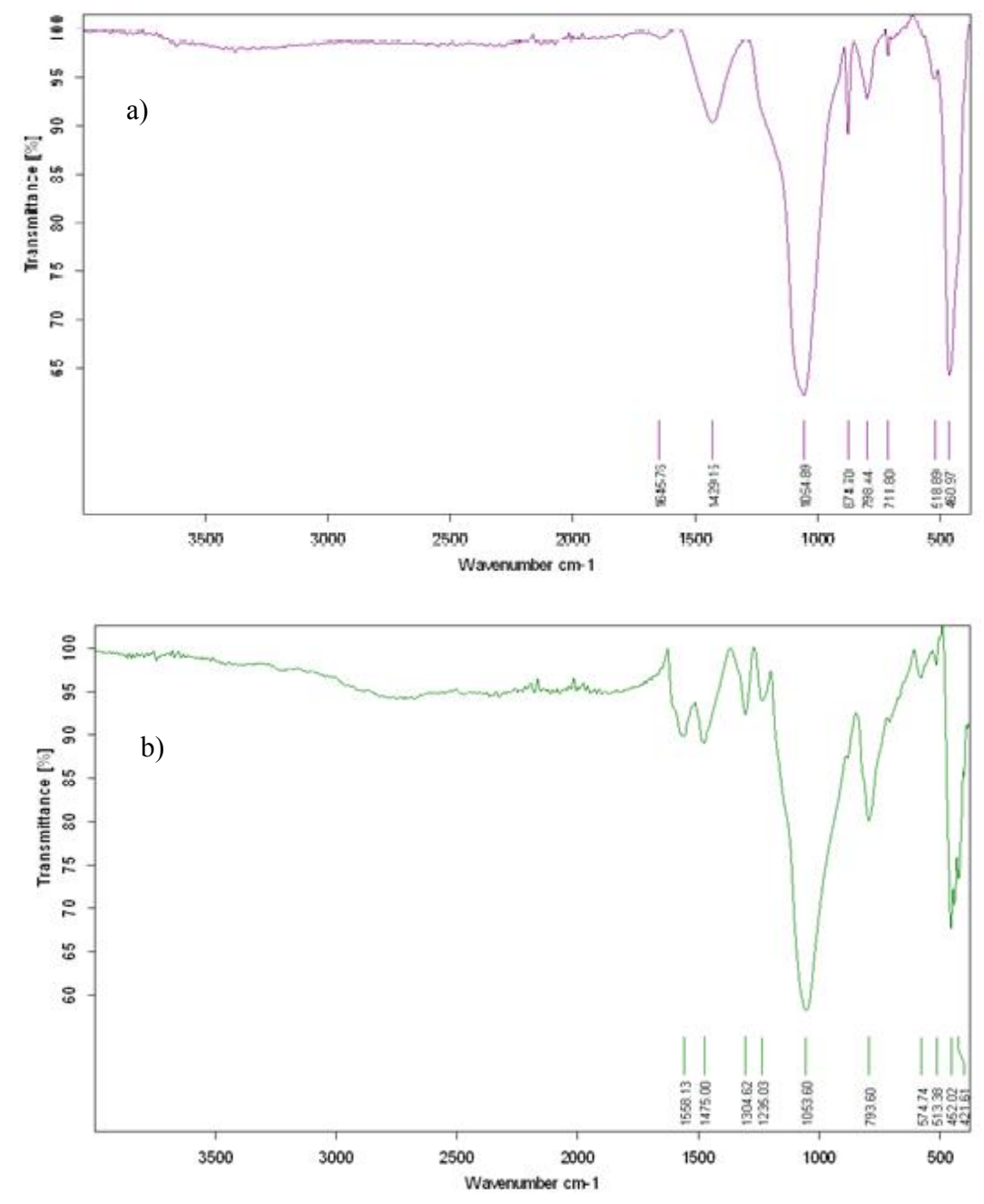

Fig. 4. FTIR spectra of diatomite (a) and PAD composite (b)

\subsection{Effect of Adsorbent Mass}

The influence of the adsorbent mass on dye removal was studied in the range of $10-60 \mathrm{mg}$ in $50 \mathrm{ml}$ of colored solution, which corresponds to the dosing rate of $0.2-1.2 \mathrm{~g} / \mathrm{l}$. The curve in Fig. 5 shows that the amounts of adsorbed dyes increase as the adsorbent doses within the solution go up. Nevertheless, it is interesting to note that the mass of $50 \mathrm{mg}(1 \mathrm{~g} / \mathrm{l})$ has proved sufficient to remove more than $72 \%$ of the color caused by the presence of both the reactive dye and the acid. It was noted that beyond a certain mass the retention rate was slightly slowed down, probably indicating the gradual saturation of the adsorption sites on the adsorbent surface. It is therefore preferable to work with adsorbent doses that are equivalent to the concentration chosen for the two dyes $(25 \mathrm{mg} / \mathrm{l})$ and to avoid any ineffective overdose. In the rest of the work, and in order to determine the adsorption capacities by saturating all the probable sites, it was decided to work with adsorbent masses equal to $50 \mathrm{mg}$.

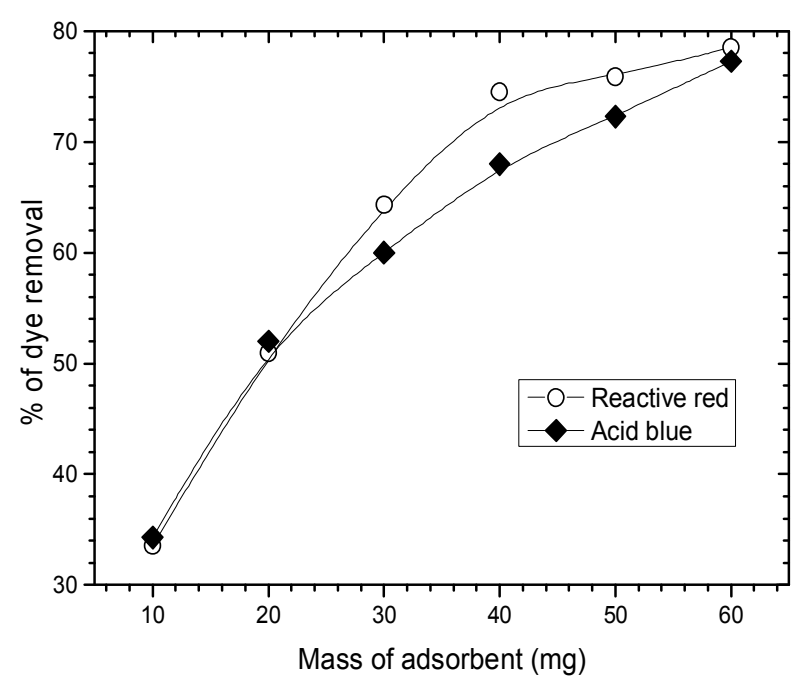

Fig. 5. Effect of the adsorbent dosage on both dyes removal in aqueous solution $\left(C_{0}=25 \mathrm{mg} / 1, V=50 \mathrm{ml}, t=1 \mathrm{~h}\right.$, $v=400 \mathrm{rpm}, \mathrm{pH}=6, T=293 \mathrm{~K})$ 


\subsection{Effect of $\mathrm{pH}$ on Dye Removal}

The influence of the initial $\mathrm{pH}$ of the solutions on adsorption was studied in the $\mathrm{pH}$ range of 3-12. The amounts of dye retained by the adsorbent from the various solutions were found to be closely related to the initial $\mathrm{pH}$ value of the solution (Fig. 6). The retention rates were found appreciable for the $\mathrm{pH}$ values between 3 and 7 for the RR dye and between 3 and 6.5 for the $\mathrm{AB}$ dye, with a retention peak towards $\mathrm{pH}=5$. A gradual decrease in efficacy was observed for the basic $\mathrm{pH}$ for both dyes; above $\mathrm{pH}=9$, a drastic decrease in efficiency was observed. Since the dyes in aqueous solution carry negative charges, it can be assumed that the adsorbent will bear varying electrical charges, depending on the solutions $\mathrm{pH}$. To find the net charge carried by the surface of the adsorbent during the fixing of dyes, it was decided to determine the point of zero charge $\left(\mathrm{pH}_{\mathrm{PZC}}\right)$, which corresponds to the $\mathrm{pH}$ value of the medium for which the resultant of all positive and negative charges (net charge) of the surface is equal to zero.

Knowing the $\mathrm{pH}_{\mathrm{PZC}}$ value is very important in order to understand the behavior of the adsorbent when electrostatic forces are involved in the attachment mechanisms. Thus, to determine the $\mathrm{pH}_{\mathrm{PZC}}, \mathrm{pH}$ tests were carried out using a simple method [21]. The method consisted in placing $50 \mathrm{ml}$ of $0.01 \mathrm{M} \mathrm{NaCl}$ solution in closed flasks and adjusting the $\mathrm{pH}$ of each solution to a given value (all values are between 3 and 12) by addition of $0.1 \mathrm{M} \mathrm{NaOH}$ or $\mathrm{HCl}$ solution. $0.15 \mathrm{~g}$ of adsorbent was introduced in each flask. The suspensions were then kept under constant stirring at room temperature for $24 \mathrm{~h}$; the final $\mathrm{pH}$ value was then noted and compared with the initial value. The $\mathrm{pH}_{\mathrm{PZC}}$ value corresponds to the point where the graph of $\mathrm{pH}_{\text {final }} v s$. $\mathrm{pH}_{\text {initial }}$ intercepts the line representing $\mathrm{pH}_{\text {final }}=\mathrm{pH}_{\text {initial }}$.

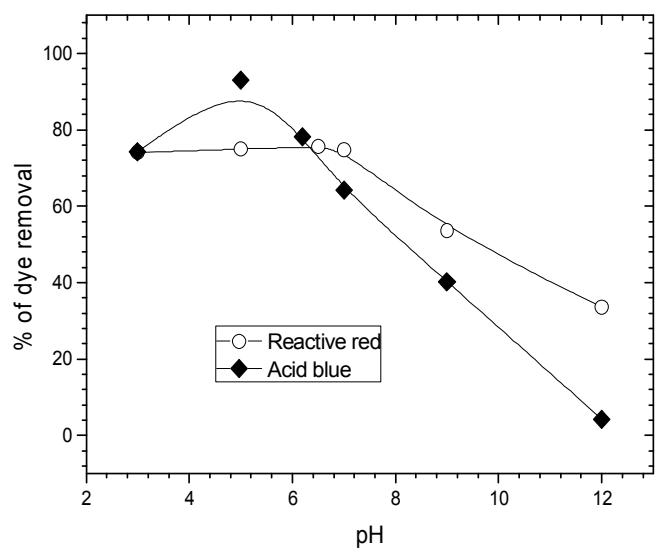

Fig. 6. Effect of initial $\mathrm{pH}$ of the solutions on elimination rate of dyes

$\left(C_{0}=25 \mathrm{mg} / 1 ; m_{\mathrm{PAD}}=0.050 \mathrm{~g} ; V=50 \mathrm{ml} ; t=1 \mathrm{~h}\right.$; $v=400 \mathrm{rpm} ; T=293 \mathrm{~K}$ )
Fig. 7 shows that the $\mathrm{pH}_{\mathrm{PZC}}$ of the $\mathrm{PAD}$ composite is equal to 7.5, which allows asserting that the adsorbent surface acquires a positive overall charge for solutions with a $\mathrm{pH}$ below this value and a negative overall charge for solutions having $\mathrm{pH}$ values above that $\mathrm{pH}_{\mathrm{PZC}}$. Since the dyes used are anionic, their dissolution in water causes the release of colored ions with a negative charge (anions). Sivaraj et al. [22] noted that the retention of acid violet 17 on an orange peel decreases with the increase in the negative charge on the surface. This means that the retention is more important when the $\mathrm{pH}$ is below the value of 7.5. In addition, the loss of efficiency when the $\mathrm{pH}$ exceeds that value indicates that the electrostatic forces between species of opposite charges play an important role in the adsorption reaction.

\subsection{Kinetics of Adsorption}

The adsorption reaction occurs between the functional groups of the adsorbent surface and the ions of dyes carrying negative charges (anions) in aqueous solution; this takes place through complexation or ion exchange with the positive charges of the surface of the adsorbent. The chemical reaction is therefore an important step in determining the mass transfer rate. Nevertheless, the diffusion processes of dye molecules that govern the transport of the dye from the volume of the solution to the surface of the solid, the diffusion of the liquid film surrounding the particles of the adsorbent or the intraparticle diffusion [23] sometimes prove to be limiting steps in the case of porous solids. In what follows, an attempt is made to adjust the adsorption process of the two dyes on the PAD to the equations describing the kinetic models of the surface reaction and those of the external and internal diffusions.

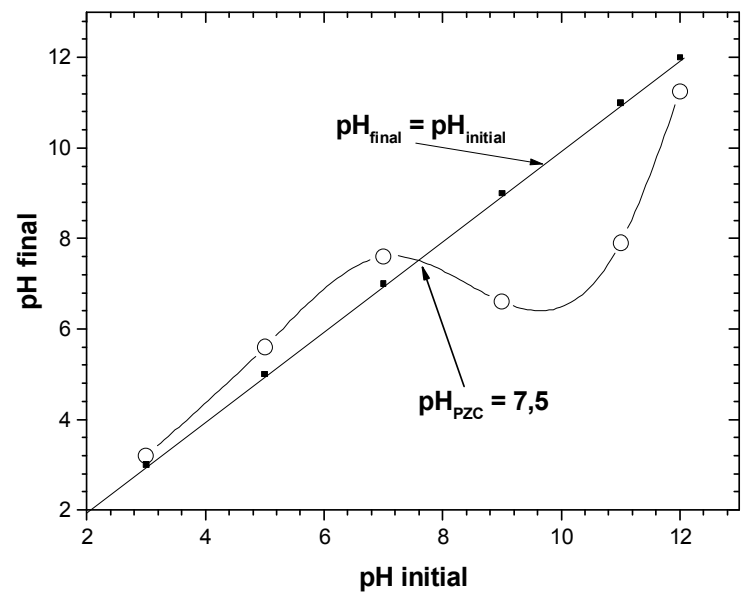

Fig. 7. The point of zero charge $\left(\mathrm{pH}_{\mathrm{PZC}}\right)$ of $\mathrm{PAD}$

The order of the reaction is a very important parameter in the determination of the reaction 
mechanisms. The adsorption-related orders that are mostly cited in the literature are:

1) The pseudo-first order which is expressed by the Lagergren equation in its expanded form [24]. It is given by the equation:

$$
\log \left(q_{e}-q_{t}\right)=\log q_{e}-\frac{k_{1}}{2.303} t
$$

The plot of $\log \left(q_{e}-q_{t}\right)$ vs. $t$ gives the line with a slope equal to $-\frac{k_{1}}{2.303}$ and an ordinate at the origin equal to $\log q_{e}$.

2) The pseudo-second order is often expressed by the following equation [25]:

$$
\frac{t}{q_{t}}=\frac{1}{k_{2} q_{e}^{2}}+\frac{1}{q_{e}} t
$$

Pseudo-second order parameters can be determined by drawing the line $\frac{t}{q_{t}} v s$. $t$, where $q_{t}$ and $q_{e}$ are the quantities adsorbed at time $t$ and at equilibrium, $k_{1}$ and $k_{2}$ are the rate constants of the pseudo-first order and pseudosecond order adsorption process, respectively.

Fig. 8 shows the effect of contact time on the retention rate of both dyes. This rate increases as the reaction time rises following two different slopes. The first one is faster and takes place during the first $30 \mathrm{~min}$, where one can notice that more than $70 \%$ of the color has been eliminated for both dyes. The second slope becomes slower as the contact time increases, suggesting that the equilibrium between retained and resorbed dye fractions is almost reached after $90 \mathrm{~min}$. The overall retention of the acid blue dye is greater than that of the reactive dye for the concentration used; it was found equal to $79 \%$ and $95 \%$ for $\mathrm{AB}$ and $\mathrm{RR}$, respectively. The adsorption capacity of two dyes at equilibrium was found to be 23.69 and $19.78 \mathrm{mg} / \mathrm{g}$, severally.

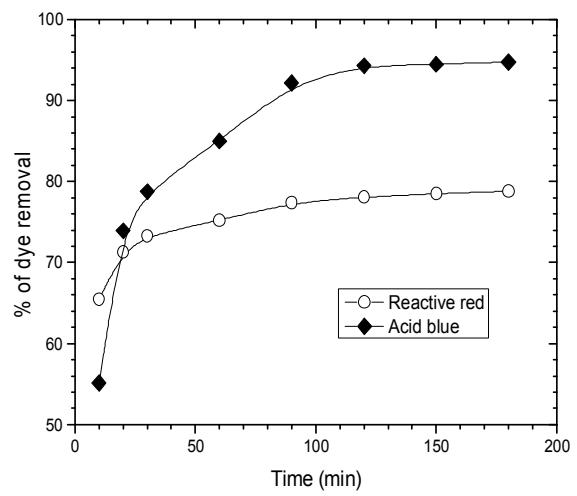

Fig. 8. Effect of contact time on the elimination of dyes $\left(C_{0}=25 \mathrm{mg} / \mathrm{l} ; m_{\mathrm{PAD}}=0.050 \mathrm{~g} ; V=100 \mathrm{ml} ; v=400 \mathrm{rpm}\right.$; $\mathrm{pH}=6 ; T=293 \mathrm{~K})$

\subsubsection{The pseudo-first order kinetics}

The pseudo-first order parameters were determined by extrapolation of the plot of the $\operatorname{line} \log \left(q_{e}-q_{t}\right)$ vs. $t$. Eqs. (5) and (6) give the values of the slopes and ordinates at the origin of these lines for the two dyes; they make it possible to determine the values of the pseudo-first order parameters at different contact times.

Reactive Red: $\log \left(q_{e}-q_{t}\right)=0.52824-0.00903 t$

Acid blue: $\log \left(q_{e}-q_{t}\right)=1.12785-0.01563 t$

The values of the adsorbed quantities $q_{e}$, the pseudo-first order constants $k_{1}$ and the regression coefficients $r^{2}$ for two dyes used are given in Table 3. The values of $r^{2}$ were found relatively low and equal to 0.9697 and 0.9822 . Furthermore, the calculation of the amounts of both adsorbed dyes $q_{e}$, which were found equal to $3.374 \mathrm{mg} / \mathrm{g}$ (RR dye) and $13.423 \mathrm{mg} / \mathrm{g}$ (AB dye), shows that these values are quite different from the experimental ones. These observations lead us to say that the adsorption of both dyes on the PAD is not adaptable to a controlled diffusion process since it does not follow the pseudo-first order equation developed by Lagergren [24].

Table 3

\begin{tabular}{|c|c|c|c|}
\hline \multirow{2}{*}{ Kinetic models } & \multirow{2}{*}{ Parameters } & \multicolumn{2}{|c|}{ Parameters values } \\
\hline & & Reactive Red & Acid Blue \\
\hline \multirow{3}{*}{ Pseudo-first order } & $\mathrm{k}_{1}, \min ^{-1}$ & 0.0207 & 0.0360 \\
\hline & $q_{e(c a l)}, \mathrm{mg} / \mathrm{g}$ & 3.374 & 13.423 \\
\hline & $r^{2}$ & 0.9823 & 0.9698 \\
\hline \multirow{3}{*}{ Pseudo-second order } & $k_{2}, \mathrm{~g} / \mathrm{mg} \cdot \min$ & 0.0142 & 0.0051 \\
\hline & $q_{e(c a l)}, \mathrm{mg} / \mathrm{g}$ & 20.096 & 24.826 \\
\hline & $r^{2}$ & 0.9998 & 0.9996 \\
\hline \multirow{3}{*}{ Intraparticle diffusion } & $k_{i d,}, \mathrm{mg} \cdot \mathrm{g}^{-1} \cdot \min ^{-1 / 2}$ & 0.2165 & - \\
\hline & $C, \mathrm{mg} / \mathrm{g}$ & 17.0259 & - \\
\hline & $r^{2}$ & 0.9676 & - \\
\hline \multirow{2}{*}{ External diffusion } & $k^{\prime}, \min ^{-1}$ & 0.0212 & 0.0389 \\
\hline & $r^{2}$ & 0.9890 & 0.9709 \\
\hline Experimental data & $q_{e(\exp )}, \mathrm{mg} / \mathrm{g}$ & 19.780 & 23.690 \\
\hline
\end{tabular}

Kinetic parameters of dyes adsorption on PAD 


\subsubsection{The pseudo-second order kinetics}

The values of the adsorbed amounts $q_{e}$, the pseudosecond order constants $k_{2}$ and the regression coefficients $r^{2}$ are given in Table 3 . In view of these results, one can say that the values of $r^{2}$ are very high and are very close to unity $\left(r^{2} \approx 1\right)$. The quantities fixed at equilibrium are around $20.096 \mathrm{mg} / \mathrm{g}$ (RR dye) and $24.826 \mathrm{mg} / \mathrm{g}$ (AB dye) and are very close to the experimental values, which are 19.78 and $23.69 \mathrm{mg} / \mathrm{g}$, respectively. These latter two observations lead us to think that the surface reaction follows the pseudo-second order model. Eqs. (7) and (8) give the values of the slopes and the ordinates at the origin of the lines $\frac{t}{q} v s$. $t$ for two dyes; this makes it possible to determine, by extrapolation, the pseudo-second order parameters, at different contact times.

$$
\begin{aligned}
& \text { Reactive Red: } \frac{t}{q}=0.17395+0.04976 t \\
& \text { Acid blue: } \frac{t}{q}=0.31348+0.04028 t
\end{aligned}
$$

\subsubsection{Diffusion process}

The retention of solutes dissolved in water (dyes in our case) by a porous solid is the result of four successive steps, which can occur either independently of each other, or simultaneously. The first one is the migration of the solute from the aqueous phase to the surface of the solid to form a film around the particles of the solid. The second one is the diffusion through inter-particle spaces (external diffusion). The third one concerns the diffusion through the intraparticle pores (internal diffusion), and the fourth and last one is the surface chemical reaction between the surface functions of the adsorbent and the active groups of the dyes. The first stage of this transfer of matter is provided by good agitation, while the last step is generally fast, which suggests that the diffusion processes are most likely to be limiting steps that control the overall process of adsorption.

The models that represent the external and intraparticle diffusion of a solute from a solution phase to a solid phase are often expressed by Eqs. (9) and (10):

$$
\begin{gathered}
\frac{\ln \left(\left(C_{0}-C_{e}\right)\right)}{\left(C_{t}-C_{e}\right)}=k\left(\frac{a}{V}\right) t=k^{\prime} t \\
q_{t}=k_{i d} t^{\frac{1}{2}}+C
\end{gathered}
$$

where $C_{0}, C_{t}$ and $C_{e}$ are the concentrations at time $t=0$, at time $t$ and at equilibrium of the solute in the solution, $\mathrm{mg} / \mathrm{l} ; a$ is the area of the solid/liquid interface, $1 / \mathrm{cm} ; V$ is the volume of the solution, $1 ; k^{\prime}$ and $k_{i d}$ are the constants of external and intraparticle diffusion velocity; $C$ is a constant.

The adjustment of the experimental points on the graphs representing the lines $\frac{\ln \left(\left(C_{0}-C_{e}\right)\right)}{\left(C_{t}-C_{e}\right)} v s . t$ and $q_{t} v s$. $\frac{1}{2}$

$t^{\overline{2}}$ allows confirming or refuting whether or not the diffusion type represents a decisive step in the overall adsorption process.

Figs. 9 and 10 show the plots of two models for both dyes used. The values of the external ( $\left.k^{\prime}\right)$ and internal $\left(k_{i d}\right)$ diffusion constants, as well as those of the regression coefficients $r^{2}$ are presented in Table 3. From these two figures, it appears that the external and intraparticle diffusions are significant steps in the process of adsorption of the RR dye on PAD. Indeed, for the latter the retention kinetics is adjustable to two diffusion models with fairly good regression coefficients, i.e. $r^{2}=0.989$ (external) and $r^{2}=0.967$ (internal). On the other hand, for the acid blue dye, which is not concerned with the intraparticle diffusion, the retention kinetics is adjustable to the external diffusion model with a fairly good regression coefficient $r^{2}=0.971$.

The difference in behavior of two dyes may be attributed to the size of their molecules; the molecule of Reactive Red is larger than that of acid blue because it contains more aromatic nuclei and sulphonic groups (Fig. 1 ); its molecular weight is twice as large (Table 2). This means that the displacement of the acidic dye molecules in the aqueous solution to reach the outer surface of the adsorbent is faster than that of the reactive dye. In addition, these molecules are not slowed by diffusion into the adsorbent pores, which is not the case of the reactive dye. This hypothesis is supported by the fact that the slope of the straight line representing the external diffusion of the acidic dye is greater than that of the reactive dye (Eqs. (11) and (12)), indicating a faster displacement.

In the case of the reactive dye, the intraparticle diffusion, expressed by Eq. (13), becomes effective only after the first $20 \mathrm{~min}$ (Fig. 10). This latency time can be explained by the easy movement of the dye molecules at the beginning of the adsorption process, before creating disorder within the micropores of the adsorbent. Nevertheless, the surface chemical reaction, which starts from the first minutes of contact time and the experimental points of which are aligned with the pseudosecond order model with very high regression coefficients $r^{2}$, indicates that the most influential step remains that of both external and intraparticle diffusion processes. These processes can be considered as limiting steps that control the transfer rate of the two dyes at each instant $t$.

$$
\begin{aligned}
& \text { Reactive Red: } \frac{\ln \left(\left(C_{0}-C_{e}\right)\right)}{\left(C_{t}-C_{e}\right)}=1.69885+0.02121 t \\
& \text { Acid blue: } \\
& \qquad \frac{\ln \left(\left(C_{0}-C_{e}\right)\right)}{\left(C_{t}-C_{e}\right)}=0.20241+0.03898 t
\end{aligned}
$$

$$
\text { Red Reactive: } q_{t}=17.02583+0.21645 t^{\frac{1}{2}}
$$




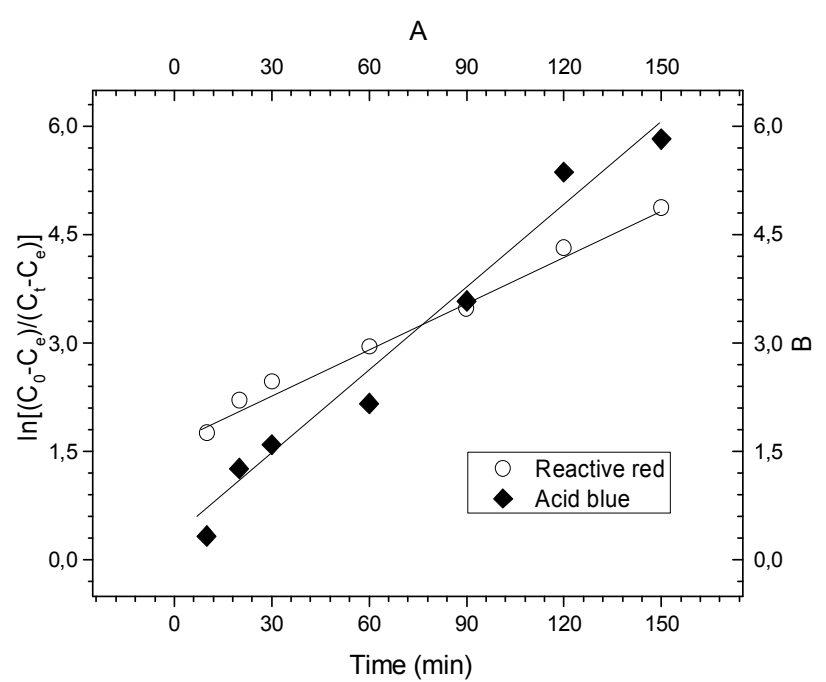

Fig. 9. Adjustment of the dyes adsorption to the external diffusion model

\subsection{Adsorption Isotherms}

These are curves that are plotted at constant temperature; they express the amounts of adsorbate extracted from the solution as a function of the residual adsorbate concentration at equilibrium $\left(q_{e}=f\left(C_{e}\right)\right)$. Fig. 11 illustrates the adsorption isotherm of two dyes RR and $\mathrm{AB}$, in the aqueous solution on the PAD. The models commonly used by researchers in expressing the adsorption isotherms of dyes on porous solids are Langmuir and Freundlich models $[15,16,26]$. This does not preclude the use of other models in order to determine the type of interaction between the molecules of dyes and the solid surface. It was therefore decided to use the following three models to express different adsorbate distributions on the adsorbent sites: Langmuir, Freundlich and BET (Brunauer, Emmet and Teller) models.

The Langmuir model considers that the surface of the solid is uniform; it expresses a monolayer affixation of the adsorbate to sites having the same energy without interactions between the adsorbed molecules. It is worth noting that the adsorption heat is independent of the surface coverage rate of the solid. The linear form of the Langmuir equation is expressed by Eqs. (14) and (15):

$$
\begin{aligned}
& \frac{C_{e}}{q_{e}}=\frac{1}{K_{L} q_{m}}+\frac{1}{q_{m}} C_{e} \\
& \frac{1}{q_{e}}=\frac{1}{q_{m}}+\frac{1}{K_{L} q_{m}} \cdot \frac{1}{C_{e}}
\end{aligned}
$$

where $q_{e}$ is the adsorption capacity at equilibrium, $\mathrm{mg} / \mathrm{g}$; $q_{m}$ is the saturation adsorption capacity, $\mathrm{mg} / \mathrm{g} ; K_{L}$ is Langmuir constant, $1 / \mathrm{mg}$.

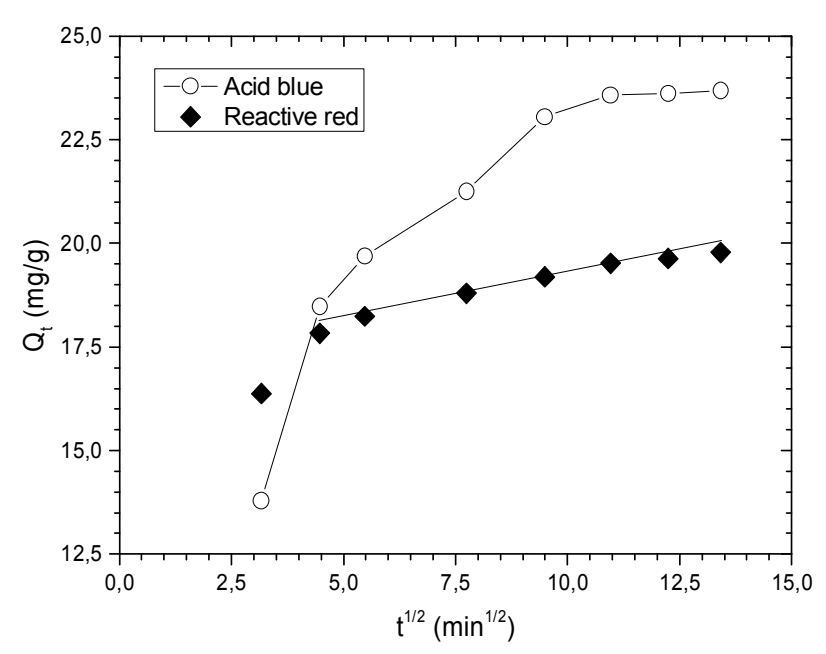

Fig. 10. Adjustment of the dyes adsorption to the intraparticle diffusion model

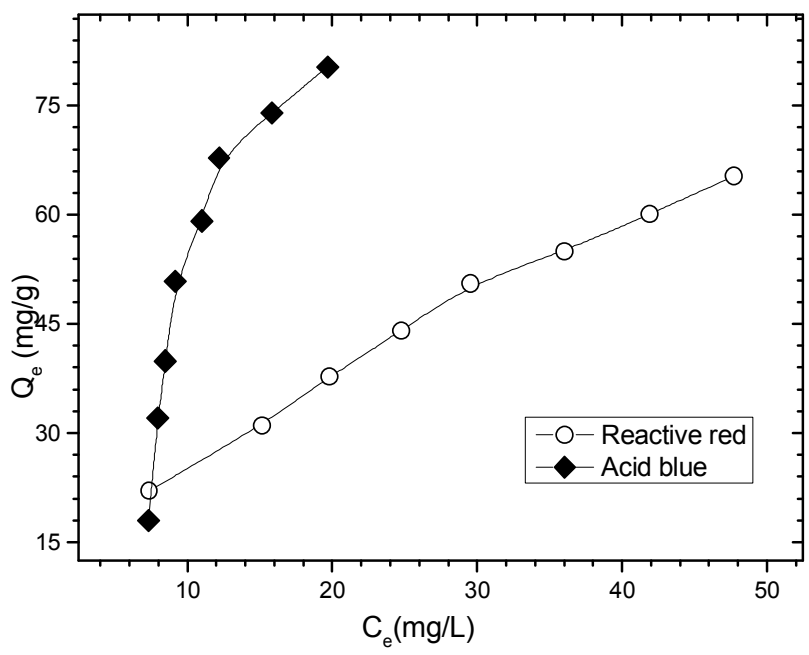

Fig. 11. Adsorption isotherms of dyes on the PAD

In order to know whether the adsorption is favorable or not according to this model, the $R_{L}$ parameter, called the equilibrium parameter, is generally used; it is expressed by the following equation:

$$
R_{L}=\frac{1}{1+K_{L} C_{0}}
$$

It is worth mentioning that the adsorption is favorable when this parameter is such that $0<R_{L}<1$ and not favorable when $R_{L}>1$. The parameters of this model may be calculated, by extrapolation, from the lines $C_{e} / q_{e}$ vs. $C_{e}$ or $1 / q_{e} v s .1 / C_{e}$.

Freundlich model assumes that the adsorbate molecules are distributed on hetero-energetic sites, with the possibility of interactions between these same molecules. According to this model, the adsorption is 
favorable when the value of the constant $1 / n$ is between 0 and 1 . The linear form of the Freundlich equation is given by Eq. (17):

$$
\log q_{e}=\log K_{F}+\frac{1}{n} \log C_{e}
$$

where $n$ and $K_{F}$ are Freundlich constants, $\mathrm{mg} / \mathrm{g} \cdot(1 / \mathrm{mg})^{1 / n}$

The parameters of this model can be computed, by extrapolation, from the $\operatorname{line} \log q_{e} v s . \log C_{e}$.

The BET (Brunauer, Emmet and Teller) adsorption isotherm is based on the hypothesis of multilayer formation. The molecules settle on each other to give an interfacial zone that can contain several layers of adsorbed molecules. The linear form of the BET equation can be expressed by Eq. (18):

$$
\frac{C_{e}}{\left(C_{s}-C_{e}\right) q_{e}}=\frac{1}{A X_{m}}+\frac{(A-1)}{A X_{m}} \frac{C_{e}}{C_{s}}
$$

where $C_{e}$ and $C_{s}$ are the solute concentrations in solution at equilibrium and after saturation, respectively, $\mathrm{mg} / \mathrm{l} ; q_{e}$ is the adsorption capacity at equilibrium, $\mathrm{mg} / \mathrm{g} ; X_{m}$ is the amount of adsorbate needed to cover the solid with a single monolayer, $\mathrm{mg} / \mathrm{g} ; A$ is the constant that describes the interaction energy between the adsorbate molecules and the adsorbent surface.

The parameters of this model can be calculated, by extrapolation, from the line $\frac{C_{e}}{\left(C_{s}-C_{e}\right) q_{e}}$ vs. $\frac{C_{e}}{C_{s}}$. The parameters of the three isothermal models are given in Table 4.

Table 4

\begin{tabular}{|c|c|c|c|}
\hline \multirow{2}{*}{ Isotherm Models } & \multirow{2}{*}{ Parameters } & \multicolumn{2}{|c|}{ Parameter values } \\
\hline & & Reactive Red & Acid Blue \\
\hline Freundlich & $\begin{array}{c}\mathrm{n} \\
K_{F}, \mathrm{mg} / \mathrm{g} \cdot(1 / \mathrm{mg})^{1 / n} \\
q_{m}, \mathrm{mg}_{r^{2}}\end{array}$ & $\begin{array}{c}1.675 \\
6.474 \\
44.195 \\
0.9929\end{array}$ & $\begin{array}{c}0.798 \\
2.424 \\
136.455 \\
0.7025\end{array}$ \\
\hline Langmuir & $\begin{array}{c}q_{m}, \mathrm{mg} / \mathrm{g} \\
K_{L}, 1 / \mathrm{mg} \\
R_{L} \\
r^{2}\end{array}$ & $\begin{array}{c}110.253 \\
0.0283 \\
0.585 \\
0.9458\end{array}$ & $\begin{array}{l}- \\
- \\
- \\
-\end{array}$ \\
\hline BET & $\begin{array}{c}X_{m}, \mathrm{mg} / \mathrm{g} \\
A \\
r^{2}\end{array}$ & $\begin{array}{l}- \\
- \\
-\end{array}$ & $\begin{array}{l}7.933 \\
-4.813 \\
0.9096\end{array}$ \\
\hline Experimental data & $q_{m(\exp )}, \mathrm{mg} / \mathrm{g}$ & 65.34 & 80.33 \\
\hline
\end{tabular}

Isotherms models applied for dyes adsorption on the PAD

Table 5

Comparative adsorption capacities of certain adsorbents

\begin{tabular}{|c|c|c|c|}
\hline Adsorbent & Dye & $q_{m}, \mathrm{mg} / \mathrm{g}$ & Reference \\
\hline $\mathrm{MgO}$ nanoparticles & $\begin{array}{l}\text { Reactive Blue } 19 \\
\text { Reactive Red } 198\end{array}$ & 50 & {$[27]$} \\
\hline Orange peels & Acid Violet 17 & 19.88 & [21] \\
\hline Calcined diatomite & $\begin{array}{c}\text { Reactive Black C-NN } \\
\text { Reactive Yellow MI-2RN }\end{array}$ & $\begin{array}{l}28.35 \\
16.99 \\
\end{array}$ & {$[15]$} \\
\hline Modified bentonite & Acid Yellow S 4GL & 64 & [28] \\
\hline Polyaniline-diatomite & $\begin{array}{l}\text { Reactive Red } 120 \\
\text { Acid Blue } 113\end{array}$ & $\begin{array}{l}65.34 \\
80.33\end{array}$ & This study \\
\hline
\end{tabular}
for basic dyes removal from aqueous solutions

It turns out that Freundlich model reflects quite well the adsorption of the RR dye. Note that the linear regression coefficient $r^{2}$ is greater than 0.993 and the adsorption capacity $\left(q_{m}=44.195 \mathrm{mg} / \mathrm{g}\right)$ is close to the experimental value. On the other hand, neither the Langmuir model nor the BET model reflects the adsorption of this dye. The Langmuir model, in spite of the acceptable linearity $\left(r^{2}=0.945\right)$, gives a calculated adsorption capacity $\left(q_{m}=110.253 \mathrm{mg} / \mathrm{g}\right)$ that is very different from the experimental value. The large molecules of RR cannot therefore be placed in a homogeneous monolayer or multilayer in the sites of the adsorbent surface. The composite that has a heterogeneous surface may explain this type of distribution of 
dye molecules. In the case of the $\mathrm{AB}$ dye, the calculated points show poor linearity for both the Freundlich and Langmuir models. The values of $r^{2}$ were found to be 0.7026 (Freundlich) and 0.9097 (BET), which indicates that the BET model is the most suitable for describing the adsorption of $\mathrm{AB}$ on the PAD. The molecules of Acid Blue, which are less voluminous and have a nearly linear form, can thus be placed in multilayers. The molecules settle on each other to give an interfacial zone that can contain several thicknesses of adsorbed molecules. Finally, as an indication, Table 5 gives a comparison between the adsorption capacities of certain adsorbents and those of the acid and reactive dyes. The adsorbent used in this work (PAD) has good adsorption capacities for these two types of dyes.

\section{Conclusions}

The synthesis of the polyaniline/diatomite (PAD) composite was achieved by modifying the diatomite using polyaniline. The characterization techniques used showed that groups on the diatomite surface have undergone a modification from the electrical charge and surface area points of view. The use of this composite in the retention of anionic azo dyes in aqueous solution gave satisfactory results, because the adsorption capacities obtained under optimal conditions were $65.34 \mathrm{mg} / \mathrm{g}$ for Reactive Red and $80.33 \mathrm{mg} / \mathrm{g}$ for Acid Blue. These adsorption capacities were very high compared to those obtained by others adsorbents. The study of the kinetics and adsorption isotherms of both dyes showed that the surface reaction follows the pseudo-second order model; it also indicated that the distribution of Reactive Red dye molecules occurs on heterogeneous energy sites following the Freundlich model, whereas the distribution of Blue Acid dye takes place in multilayers according to the BET model.

\section{Acknowledgements}

The authors would like to warmly thank the Directorate General for Scientific Research and Technological Development (Algeria), the Ministry of Higher Education and Scientific Research (Algeria) for their financial assistance, as well as the Research Center in Physical-Chemical Analysis (Algeria), for their assistance with the analysis and characterization techniques.

\section{References}

[1] Dutta J., Ahmed A.: J. Chem. Pharm. Res., 2016, 8, 93.

[2] Lee Y., Spyros H., Pavlostathis G.: Water Res., 2004, 38, 1838. https://doi.org/10.1016/j.watres.2003.12.028

[3] Crini G.: Bioresour. Technol., 2006, 97, 1061.

https://doi.org/10.1016/j.biortech.2005.05.001

[4] Gupta V., Suhas K.: J. Environ. Manag., 2009, 90, 2313.

https://doi.org/10.1016/j.jenvman.2008.11.017

[5] Wu J., Yang Y., Lin J.: J. Hazard. Mater., 2005, B127, 196.

https://doi.org/10.1016/j.jhazmat.2005.07.016

[6] Dabrowski A.: Adv. Colloid Int. Sci., 2001, 93, 135.

https://doi.org/10.1016/S0001-8686(00)00082-8

[7] Aivalioti M., Vamvasakis I., Gidarakos E.: J. Hazard. Mater., 2010, 178, 136. https://doi.org/10.1016/j.jhazmat.2010.01.053

[8] Arik H.: J. Eur. Ceramic Soc., 2003, 23, 2005.

https://doi.org/10.1016/S0955-2219(03)00038-4

[9] Paschen S.: Erzmetall, 1986, 39, 158.

[10] Elden H., Morsy G., Bakr M.: Asi. J. Mater. Sci., 2010, 2, 121. https://doi.org/10.3923/ajmskr.2010.121.136

[11] Alahiane S., Qourzal S., Sennaoui A. et al.: J. Mater. Environ. Sci., 2016, 7, 638.

[12] Ayaz N., Thankappan R., Srinivasan S.., Tamilselvi A.: Int. J. Innovative Res. Sci. Eng. Technol., 2015, 4, 938. https://doi.org 10.15680/IJIRSET.2015.0403021

[13] Bouyakoub A., Kacha S., Lartiges B. et al.: Desal. Water Treat., 2009, 12, 202. https://doi.org/10.5004/dwt.2009.934

[14] Kacha S., Derriche Z., Elmaleh S.: Water Environ. Res., 2003, 75, 15. https://www.jstor.org/stable/25045657

[15] Khraisheh M., Al-ghouti M., Allen S., Ahmad M.: Water Res., 2005, 39, 922. https://doi.org/10.1016/j.watres.2004.12.008

[16] Jian Z., Qingwei P., Meihong N. et al.: Appl. Clay Sci., 2013, 83-84, 12. https://doi.org/10.1016/j.clay.2013.08.008

[17] Li X., Bian C., Chen W. et al.: Appl. Surf. Sci., 2003, 207, 378. https://doi.org/10.1016/S0169-4332(03)00010-2

[18] Li X., Li X., Wang G.: Mater. Chem. Phys., 2007, 102, 140. https://doi.org/10.1016/j.matchemphys.2006.11.014

[19] Bouyakoub A., Lartiges B., Ouhib R. et al.: J. Hazard. Mater., 2011, 187, 264. https://doi.org/10.1016/j.jhazmat.2011.01.008

[20] Gao B., Jiang P., An F. et al.: Appl. Surf. Sci., 2005, 250, 273. https://doi.org/10.1016/j.apsusc.2005.02.119

[21] Belaid K., Kacha S.: J. Water Sci., 2011, 24, 131.

https://doi.org/10.7202/1006107ar

[22] Sivaraj R., Namasivayam C., Kadirvelu K.: Waste Manag., 2001, 21, 105.

https://doi.org/10.1016/S0956-053X(00)00076-3

[23] Al-ghouti M., Khraisheh M., Ahmad M., Allen S.: J. Hazard.

Mater., 2009, 165, 589.

https://doi.org/10.1016/j.jhazmat.2008.10.018

[24] Lagergren S.: K. Sven. Vetenskapsakademiens Handl., 1898, 24, 1.

[25] Ho Y., McKay G.: Process Biochem., 1999, 34, 451.

https://doi.org/10.1016/S0032-9592(98)00112-5

[26] Sari A., Demirhan C., Mustafa T.: Chem. Eng. J., 2010, 162,

21. https://doi.org/10.1016/j.cej.2010.05.054 
[27] Moussavi G., Mahmoudi M.: J. Hazard. Mater., 2009, 168, 806. https://doi.org/10.1016/j.jhazmat.2009.02.097

[28] Bouberka Z., Kacha S., Kameche M. et al: J. Hazard. Mater., 2005, 119, 117. https://doi.org/10.1016/j.jhazmat.2004.11.026

Received: April 23, 2019 / Revised: May 11, 2019 / Accepted: September 17, 2019

\section{СИНТЕЗ, ХАРАКТЕРИСТИКА І ЗАСТОСУВАННЯ} КОМПОЗИТА НА ОСНОВІ ДІАТОМІТУ ДЛЯ АДСОРБЦІї АНІОННИХ БАРВНИКІВ У ВОДНИХ РОЗЧИНАХ

Анотація. Композит поліанілін-діатоміт (ПАД) синтезовано іn-situ полімеризацією аніліну та визначено його ха- рактеристику і показано застосування при адсорбиії барвників реактивного червоного 120 (RR 120) та кислотно-синього (AB). Для одержання композиту очищений діатоміт змімували 3 розчином, щзо містить анілін, розчинений у 2 М хлорній кислоті за кімнатної температури. Характеристику отриманого твердого продукту проведено за допомогою скануючої електронної мікроскопії, рентгенівського аналізу та Фур ‘еспектроскопї. За допомогою кінетичної моделі псевдодругого порядку описано кінетичну адсорбиію барвників. Показано, щзо ізотерма адсорбиії барвника RR 120 відповідає адсорбиіній моделі Фрейндліха, а ізотерма барвника $A B$ може краще відповідає моделі БЕТ.

Ключові слова: адсорбція, аніонні барвники, характеристика, діатоміт, поліанілін, синтез. 